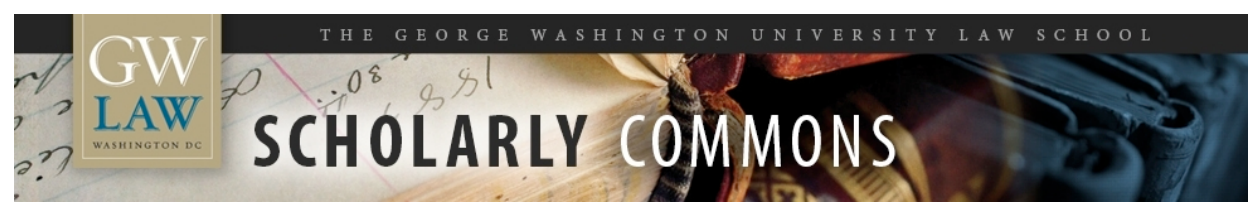

\title{
The 'Wildavsky Heuristic': The Cultural Orientation of Mass Political Opinion
}

\author{
Donald Braman \\ George Washington University Law School, dbraman@law.gwu.edu \\ John Gastil
}

Dan M. Kahan

Paul Slovic

Follow this and additional works at: https://scholarship.law.gwu.edu/faculty_publications

Part of the Law Commons

\section{Recommended Citation}

Braman, Donald; Gastil, John; Kahan, Dan M.; and Slovic, Paul, "The 'Wildavsky Heuristic': The Cultural Orientation of Mass Political Opinion" (2005). GW Law Faculty Publications \& Other Works. 202. https://scholarship.law.gwu.edu/faculty_publications/202

This Article is brought to you for free and open access by the Faculty Scholarship at Scholarly Commons. It has been accepted for inclusion in GW Law Faculty Publications \& Other Works by an authorized administrator of Scholarly Commons. For more information, please contact spagel@law.gwu.edu. 
PRELIMINARY DRAFT

October 15, 2005

\author{
The "Wildavsky Heuristic" and the \\ Cultural Orientation of Mass Political Opinion
}

John Gastil

Associate Professor, Department of Communication

Adjunct Professor, Department of Political Science

Mail: University of Washington, Box 353740, Seattle, WA 98195

Email: jgastil@washington.edu Phone: 206-543-2660 Fax: 206-616-3762

Don Braman

Irving S. Ribicoff Fellow

Yale Law School

Dan Kahan

Elizabeth K. Dollard Professor of Law

Yale Law School

Paul Slovic

Professor, Department of Psychology

University of Oregon

Authors' Note. This study was supported with funding from the National Science Foundation (Award \#0242106). The authors wish to thank John Darley, Don Green, Paul Sniderman, and Christopher Winship for their invaluable guidance as members of the study advisory panel, and the staff at Northwest Survey \& Data Services for collecting the phone-survey data. Jeffrey Rachlinski and Cindy Simmons provided useful insights on an earlier version of this paper. 


\author{
The "Wildavsky Heuristic" and the \\ Cultural Orientation of Mass Political Opinion
}

\begin{abstract}
In a provocative 1987 article, Aaron Wildavsky asserted that culture operates as the fundamental orienting force in the generation of mass public opinion. The meanings and interpersonal associations that inhere in discrete ways of life, he argued, shape the heuristic processes by which politically unsophisticated individuals, in particular, choose what policies and candidates to support. We systematize Wildavsky's theory and integrate it with existing accounts of mass opinion formation. We also present the results of an original national survey $(N=1843)$, which found that the cultural orientations featured in Wildavsky's writings accounted for policy-related attitudes on gun control, environment, capital punishment, and gay marriage, even at low levels of political sophistication and after controlling for demographics, left-right ideology, and partisanship. By contrast, much of the predictive power of demographics, left-right ideology, and partisanship on policy attitudes dissipated after taking into account cultural orientations.
\end{abstract}


Is the American electorate culturally divided? The question itself polarizes professional observers of American politics. The idea that American citizens are fighting a pitched "culture war" dominates journalistic accounts (e.g., Frank 2004) of American politics, and of the results of the 2004 election in particular. It also finds modest support in at least some academic writings (e.g., Lakoff 2002; Gusfield 1986; Hunter 1991).

The prevailing wisdom among political scientists, however, is to the contrary. As Fiorina, Abrams, and Pope (2004) write, "The simple truth is that there is no culture war in the United States . no battle for the soul of America rages, at least none that most Americans are aware of' (7-8). Decades' worth of data show that the majority of citizens hold relatively moderate views and, more importantly, lack interest in highly charged symbolic issues (DiMaggio et al. 1996; Fiorina et al. 2004; Wolfe 1999). The position of the major parties on gay marriage, the teaching of evolution in public schools, and even abortion is of consequence to only a relatively small group of intensely partisan and politically active voters and elites. The concerns of these cultural zealots receive exaggerated attention only because the non-ideological masses remain more or less evenly split on which party can best secure their mundane material needs (Fiorina et al. 2004; Hetherington 2001; Jacoby 1995).

So which is it-“moral values" or "the economy, stupid!"? We argue that the preferences of the American electorate derive from a complex and largely cognitive synthesis of cultural and material concerns. Culture does matter, a lot, for average citizens, as well for partisan ideologues. But the way in which it matters is grossly misrepresented by the popular "culture war" metaphor. Cultural values do not so much motivate citizens as orient them. Citizens are guided by the stances political parties take on cultural issues not because citizens want to ram their values down their neighbors' throats, but because they see the congeniality of a candidate's worldview as the best evidence that he or she can be relied on to put food on their table. As a result, even citizens who are relatively tolerant of — or simply indifferent to - the values of persons who harbor cultural commitments alien to their own will find themselves consistently arrayed against those persons as they attend in common to their material needs.

In advancing this account, and supporting it with empirical evidence, we mean to be vindicating a theory, not inventing one. In a 1987 article, “Choosing Preferences by Constructing Institutions: A Cultural Theory of Preference Formation," Aaron Wildavsky proposed exactly this understanding of culture and mass political opinion. Wildavsky $(1987,4)$ dismissed the utility of rational choice accounts not because he rejected their premise that individuals "prefer" what is in their "interests" but because such accounts offer no 
account of "how people figure out what their interest are." Most persons lack the time, inclination, and capacity, he observed, to derive policy positions from abstract ideological principles, or to sort through the empirical claims advanced in technical policy debates. In contrast, the values implicit in individuals' day-today social relations are readily accessible to them, as are the opinions of those who share their values. These cultural cues naturally guide individuals as they figure out what position on political issues will best promote their well-being. It is through the orienting force of culture, Wildavsky argued, "ordinary folk" are able "to generate miles of preferences" from only "inches of fact" (Wildavsky 1987, 8).

Wildavsky had at his disposal only a modest amount of evidence to back up his conjecture. In the years since he proposed it, however, the beginning of a solid empirical foundation has been laid. Some of the support comes from the field of political psychology, which has shown that individuals of modest political sophistication do indeed make extensive use of heuristics, or mental "shortcuts," to form positions (Sniderman et al. 1991). Additional confirmation comes from another field of interest to Wildavsky: risk perception (e.g., Douglas and Wildavsky 1982). Wildavsky asserted that culture plays a similar role in explaining individuals' opinions about what sorts of societal hazards are serious and worthy of regulatory amelioration. Scholars have demonstrated cultural worldviews do indeed play an orienting role in the formation of such beliefs (e.g., Dake 1991; Ellis and Thompson 1997; Peters and Slovic 1996).

We aim to advance Wildavsky's thesis on the cultural orientation of mass political opinion by synthesizing these two bodies of research. In effect, cultural worldviews of a particular sort decisively calibrate public opinion heuristics, which in turn operate as the cognitive and affective mechanisms through which culture orients attitudes. To make the case for this conception of public opinion, we begin with a theoretical overview of how this process, which we call the "Wildavsky heuristic," relates to existing accounts of mass political opinion. We then describe the results of a national survey that confirms that public opinion does, indeed, have the shape one would predict were mass opinion indeed influenced by the Wildavsky heuristic.

\section{THEORETICAL BACKGROUND}

\section{The Ignorant Masses and Their Heuristics}

The study of mass political opinion rests on an unassailable foundational insight: Most Americans are thoroughly unengaged in matters political. The modern articulation of this view traces back to Converse (1964), whose ground-breaking opinion surveys demonstrated that most American had little comprehension 
of the distinctions between liberal and conservative ideals, could not accurately associate policy positions with major parties or political figures, and displayed almost no consistency in their own positions over time or across related issues. Subject to immense controversy at the time he propounded it, Converse's "minimalist" picture (Sniderman et al. 1991) of American political consciousness has now become the established wisdom (Kinder 1998). His insights have been refined and extended, most significantly through work that shows that conventional "liberal" and "conservative" measures explain the political attitudes of only highly sophisticated and partisan members of the population and have almost no predictive power for the bulk of unsophisticated citizens (e.g., Delli Carpini and Keeter 1996; Zaller 1992).

However embarrassing it might be, the finding that most Americans are "innocent of ideology" (Kinder and Sears 1985) is hardly surprising. Even in a democracy, individual citizens have precious little influence over the content of government policy. A butcher, a baker, or a candlestick maker, intent on living well, can almost certainly find more profitable uses for her time than mastering the logic of abstract political concepts or digesting all the facts pertinent to national security or crime control. Aside from those who participate in governance or who are paid to influence (or maybe just study) those who do, persons who expend the effort to form wide-ranging, ideologically coherent policy opinions do so as a hobby. And for most people, politics is simply a less compelling hobby than sports, sailing, or card-playing - about which their views might well be immensely sophisticated.

Nevertheless, Converse's minimalist picture does create a puzzle. The vast run of citizens are not political philosophers and do not know much about policy; that is established. But the fact remains that mass opinion is not mere noise and static. People, even the non-elite masses, have political tastes the general outlines of which are discernable and relatively stable (Goren 2004). If that weren't the case, electoral politics would be chaos; there certainly would be no profession — much less a highly lucrative one —of democratic campaign management if mass opinion were completely formless and impervious to any degree of manipulation. What makes it possible for the mass of citizens, who are not political philosophers or policy wonks, to make sense of politics in way that clearly is sensible to those who are political experts?

The answer, according to a growing body of research, is the public's reliance on heuristics. "Heuristics," Sniderman et al. $(1991,19)$ explain, "are judgmental shortcuts, efficient ways to organize and simplify political choices, efficient in the double sense of requiring relatively little information to execute, yet yielding dependable answers even to complex problems of choice." Lacking political knowledge and the 
incentive and time to acquire it, the vast majority of citizens "substitute low-cost cues for the detailed information that they lack" (Lupia 2002, 55).

Political scientists and social psychologists have catalogued a vast number of such heuristic processes. Lupia $(1994,2002)$, for example, focuses on the disposition of members of the public to adopt or reject the positions of individuals (or even organized groups, such as trial lawyers or insurance firms) depending on whether they perceive those individuals (or groups) to be knowledgeable and share their interests. Sniderman et al. (1991) emphasize affect: the public's viscerally positive or negative responses to the meanings that policies express, or to the groups who either oppose or support those policies, steer mass opinion down predictable pathways. Others have shown that individuals tend to select and credit like-minded information sources, both interpersonal (Mutz 2002; Mutz and Martin 2001) and mediated (Pew Research Center 2004).

The most systematic account of how heuristic reasoning schemes substitute for and interact with political sophistication is Zaller's "Receive-Accept-Sample" (RAS) Model (Zaller 1992). The "sample" component refers to the heuristic influence of "salience" and "availability" (see generally Tversky and Kahneman 1973): When individuals are required to express an opinion on a political issue, Zaller asserts, they "do not normally canvass their minds for all considerations" but instead respond "on the basis of whatever considerations are accessible 'at the top of the head.' " (Zaller 1992, 49). Their mental inventories of accessible opinions are shaped by the persuasive and informational messages they "receive" and "accept"- the "RA" portion of the RAS Model. Such messages pour out from various media, elite, and common sources. What messages individuals accept (and thereby absorb) depends on the operation of various heuristics, including their affective orientation toward the political affiliation or leanings of the message source. People reject "arguments that are inconsistent with their political predispositions," at least to the extent that they are sophisticated enough "to perceive a relationship between the message and their predispositions" (Zaller 1992, 44). In this way, individuals' stores of readily available, issue-relevant considerations accumulate in patterns that conform more or less coherently with their predispositions.

But at the same time heuristic accounts of opinion formation solve one mystery — how there can be any rhyme or reason in mass opinion given how minimally sophisticated most citizens are they create a host of new ones. Heuristics do not always depend on expertise, but they clearly depend on something. Why do citizens have a visceral "like" or "dislike" for certain clusters of policies? Why do individuals tend to seek out and accept information more readily from ideologically like-minded associates? Indeed, how do citizens 
even identify which sources are ideologically congenial to them if they are "innocent of ideology"? The idea that they defer to "knowledgeable" persons who "share their interests" is similarly puzzling: how do persons who lack the time and capacity to become experts themselves have the time and capacity to figure out which policy experts are credible when (as is inevitably the case) such experts disagree on economics, national security, crime control and the like?

For all its strengths, the RAS model presupposes rather than supplies the answer to these questions. Zaller suggests that the heuristic processing of information is guided by citizens' "predispositions." However, Zaller never clearly distinguishes between "predispositions" from ideology. Indeed, he comes close to treating them as one and the same: "ideology," "values," and terms like "liberal" and "conservative" can all be used interchangeably, he writes, as "indicators of predispositions to accept or reject particular political communications" (Zaller 1992, 28); throughout his analysis, moreover, he tends to use a simple leftright continuum measure as the primary operational definition of predisposition. Nevertheless, Zaller cannot truly mean to argue that ideology orients heuristics, for heuristics are supposed to be the phenomena that allows individuals who lack genuine ideological facility to form coherent opinions.

Within RAS, then, "predispositions" operate as a sort of placeholder for some unspecified sensibility distinct from ideology (and from liberal and conservative self-identification) that makes it possible for those who lack political sophistication to form relatively coherent political opinions. Just as the orbital patterns of known planets in the solar system cannot be accounted for without positing the gravitational perturbations of an as-yet undiscovered "Planet X," so the regularities imparted to mass opinions by heuristics imply the existence of another, as-yet uncharted attitudinal force that orients these heuristics and sets their valences.

\section{Wildavsky's Conjecture: The Cultural Endogeneity of Preferences-and Heuristics}

For Wildavsky, the "Planet X" of mass political opinion was culture. In a 1987 essay that was as much manifesto as scholarly paper (indeed, it was essentially the text of his presidential address at the $82^{\text {nd }}$ meeting of the American Political Science Foundation), Wildavsky $(1987,5)$ posited that the reciprocal interaction of distinctive forms of "social relations" and "shared values" supplies ordinary individuals with the tools they need to fabricate all manner of political opinion.

Wildavsky was motivated to look to culture to remedy what he perceived as the main defect in the then-dominant rational choice models of political action. Those theories, he wrote, attribute political behavior to "interests," yet steadfastly refuse to specify "how people figure out what their interests are" (Wildavsky 1987, 4). “Ask an economist where preferences come from," he wrote, "and you will be told that 
they are exogenous, external to the system being considered;" thus, the "least interesting behavior, instrumental actions, may be explained by preferences; but about the most interesting [matter], preferences themselves, nothing at all can be said" (4-5). "Cultural theory, by contrast, is based on the premise that preferences are endogenous - internal to organizations - so that they emerge from social interaction in defending or opposing different ways of life" (5). By categorizing the "ways of life" that lie behind the apprehension of interests, "cultural theory [can] explain and predict recurrent regularities" in political behavior that rational choice theories take as given (Ibid.).

Wildavsky's conception of "culture theory" rested on a scheme developed by anthropologist Mary Douglas (1982). Douglas's typology characterizes cultures or “ways of life," and associated "worldviews," along two cross-cutting dimensions, "group" and "grid." "The group dimension represents the degree to which "the individual's life is absorbed in and sustained by group membership" (Douglas 1982, 202). Those who adhere to a low group or individualistic way of life prize "self-regulation," and "favor bidding and bargaining" over collectively dictated allocations of resources (Wildavsky 1987, 6); those who live within a strong group or solidaristic way of life "depend on each other" to secure their collective needs, a condition that "promotes values of solidarity" (Rayner 1992, 86). The grid dimension measures the pervasiveness and significance of social differentiation within a way of life. Low grid ways of life generate preferences for "an egalitarian culture" that sets itself in opposition to "differences_-between races, or income levels, or men and women, parents ad children, teachers and students, authorities and citizens" (Wildavsky 1987, 7). High grid ways of life, in contrast, imbue individuals with a hierarchical worldview that "justifies inequality on grounds that specialization and division of labor enable people to live together with greater harmony and effectiveness" (Ibid.).

Writing at about the time heuristics were first being proposed as the solution to the puzzle of minimalism, Wildavsky offered essentially a heuristic account of how these cultural outlooks generate political opinions. "A basic reason people are able to develop so many [policy] preferences," he argued, "is that they actually do not have to work all that hard" (Wildavsky 1987, 8). The values that inhere in a person's preferred way of life are woven into the fabric of his everyday existence. Accordingly, "without knowing much about [a proposed policy,] those who identify with each particular way of life," simply by considering the social meaning or resonance of the policy, can usually "guess whether its effect is to increase or decrease social distinctions, impose, avoid, or reject authority" (7): “A few positive and negative associations go a long way" (8). Moreover, because the cultural proclivities of others are likewise readily apparent from their 
ordinary life behavior, anyone who harbors any doubt about the meaning of a policy proposal need merely "observ[e] what like-minded individuals" or unlike-minded ones have to say: "The stock phrases 'one of us' versus 'one of them' go a long way" too (Ibid.).

As any political scientists after Converse could tell us, ordinary citizens cannot furnish cogent accounts of liberalism or conservativism, much less derive policy positions from them. But it is a mistake, Wildavsky $(1987,9)$ argued, to think that any such facility is required to be generate coherent political opinions: "It is no more necessary for a person to verbalize about culture than it is necessary to know the rules of grammar in order to speak." Wildavsky $(1987,8)$ explained that "by figuring out their master preferences, as it were - who they are and are not, to what groups they do and do not belong - they can readily figure out the rest."

But unlike other budding heuristicists, Wildavsky readily perceived the niggling incompleteness of such theories; indeed, he presented his own "cultural theory of preference formation" as supplying the answer to the questions that heuristic accounts seem to beg. The affect heuristic tells us that individuals will support the policy clusters they "like," the credibility heuristic that they'll defer to the advocates they trust, etc. But culture theory — of the sort associated with Douglas's group-grid scheme - tells us what it is that individuals like about those policies, who it is they trust, and why and how those and like dispositions vary across individuals. "Cultural theory attempts to unify heuristics by suggesting that these chains have but one link: the internalization of social relations" (Wildavsky 1987, 10). Essentially, for Wildavsky, preferences are endogenous to culture because the heuristic mechanisms by which preferences are formed are endogenous to culture too.

Wildavsky (1987) offered a strikingly bold vision of the logic of mass political opinion. All it lacked was evidence.

\section{The Cultural Theory of Risk Perception}

But in fact, a good deal of indirect evidence was under development in another field of immense interest to Wildavsky: risk perception. In Risk and Culture: An Essay on The Selection of Technical and Environmental Dangers (1982), Wildavsky and Mary Douglas used Douglas's group-grid scheme to explain conflict over the regulation of environmental and technological risks in the United States. The basic claim was that individuals selectively credit claims of societal danger in a manner that reflects and reinforces their preferred way of life. Thus, egalitarians and solidarists, they argued, are naturally sensitive to environmental risk, the reduction of which justifies regulating commercial activities that are productive of social inequality 
and that legitimize unconstrained self-interest. Individualists, in contrast, predictably dismiss claims of environmental risk as specious, in line with their commitment to the autonomy of markets and other private orderings. So do hierarchists, who perceive warnings of imminent environmental catastrophe as threatening the competence of social and governmental elites.

Risk and Culture was only thinly empirical — and was indeed denounced as a polemic by environmentalists - but within a short period of time its central claims were vindicated through survey research. The first studies were done by Dake (1991) in collaboration with Wildavsky (Dake and Wildavsky 1990). Later researchers extended this research, confirming that the cultural worldviews associated with the group-grid typology do indeed explain variance in perceptions of environmental and various other types of risk, and explain it more powerfully than myriad other characteristics, including ideology, education, income, gender, race, and various personality traits (e.g., Ellis and Thompson 1997; Jenkins-Smith and Smith 1994; Marris et al. 1998; Peters and Slovic 1996).

These works have employed a powerful if indirect strategy of proof. Using survey methods, they have shown that risk perceptions are distributed across persons in patterns that are most readily explained by the hypothesized tendency of cultural worldviews to skew individuals' processing of information. None of these studies, however, has attempted to isolate the precise mechanisms through culture might exert this influence (a matter more fit for examination by experimental methods, as we emphasize in the Discussion section).

It is well established, though, that risk perceptions-like mass political opinions - reflect the influence of myriad heuristics, including affect (Slovic, Finucane, Peters and MacGregor 2004) and various forms of biased information processing (Slovic 2000). A plausible conjecture, then, is that these cognitive mechanisms mediate the influence of cultural worldviews, which determine the valence of such mechanisms within particular individuals (Braman, Kahan and Grimmelman, 2005). Indeed, Douglas (1999), reacting to the emergence of heuristic accounts of risk perception, ventured exactly this hypothesis.

As should be evident, the cultural theory of political preferences that Wildavsky propounded in his 1987 article is simply his and Douglas's cultural theory of risk generalized to all forms of political opinion. Just as the cultural worldviews defined by group grid can be understood to orient the various cognitive mechanisms that shape individual reactions to asserted environmental hazards, so can these worldviews be understood to orient the various heuristics that influence how individuals react to political controversies. Had Wildavsky's life not been cut short by cancer in 1993, he might well have attempted to extend to this cultural 
theory of political preferences the empirical proof he had started to develop (and which he briefly highlighted in the 1987 article) for the cultural theory of risk perception.

\section{A Synthesis: The Cultural Orientation of Mass Political Opinion}

Our aim is to commence the development of such a proof. To frame that task, we start with a relatively parsimonious model of political preference formation derived from a synthesis of Wildavsky's 1987 article and related writings, the abundant work that has been done since then on political opinion heuristics, and the empirical studies that Wildavsky and others have done on the cultural theory of risk perception.

The "Wildavsky Heuristic Model" (WHM) presupposes that individuals are differentiated by their cultural identities. Faithful to Wildavsky's position, and consistent with Douglas's typology, these identities are assumed to correspond to the ways of life associated with the "group-grid" scheme: "Though we can imagine an infinite number of potential cultures," Wildavsky $(1987,6)$ wrote, “only a few conjunctions of shared values and their corresponding social relations are viable." It is also assumed that, as a result of their interdependence and their distinctive contributions to social order, all four of the quadrants formed by the intersection of group and grid will be reasonably well populated (Thompson, Ellis and Wildavsky 1990).

Individuals' cultural identities influence their political opinions, according to WHM, through the mediation of various cognitive and social mechanisms. Culture, on this account, is seen not as an alternative to but rather as the central unifying component of the heuristic formation of political preferences. Individuals' simple apprehension of "who they are and are not, to what groups they do and do not belong" (Wildavsky 1987, 8) orients them in public life. Culture determines the valence of their affective response to policy proposals and advocates (Sniderman et al. 1991), guides their selective search for and receptivity to information (Graber 2004; Mutz and Martin 2001; Eagly and Chaiken 1993), informs their perceptions of which advocates are credible (Lupia 1994), and stocks the inventory of considerations individuals draw from (Zaller 1992) when they must ultimately take a stance on some contested issue.

"Liberal" and "conservative" self-identification exerts a force on political opinions but a relatively minor one. Its power is limited partly because, as Converse (1964) and his successors have established, only a small fraction of the population is capable of coherent ideological reasoning; thus, the power of liberalismconservativism to shape opinion is conditional on political sophistication (Delli Carpini and Keeter 1996). It is precisely because culture's power to shape opinion does not depend on political sophistication that its 
influence on mass political opinion is presumed to be more fundamental than conventional left-right ideological classifications.

In addition, liberal-conservative self-identification exerts a small influence relative to culture because the former is at least in part a consequence of the latter. This is so, we conjecture, not only for the small fraction of the population that thinks "ideologically" but also for the overwhelming majority that does not. As Herrera $(1996,621)$ put it in his study of communication between elites and masses, "Political discourse in America centers largely around the use of the terms liberal and conservative as a sort of political shorthand." What that shorthand conveys, albeit coarsely, is the content of one's cultural identity. If this is correct, then the liberal-conservative self-description will have relatively little independent predictive power for anyone — however politically sophisticated—once cultural worldviews are taken into account.

We hypothesize that partisanship, itself a predictor of liberal-conservative self-labeling, is also a direct consequence of one's cultural worldview. As conventionally conceptualized and measured, partisanship is all at once a cognitive self-labeling (thinking of oneself as a Republican), a verbal selfexpression (saying to an interviewer or fellow citizen, "I am a Republican"), and a pattern of social association (seeking the company of self-described Republicans). Though much of one's partisan identification comes as inheritance from one's parents, political socialization research has demonstrated that as offspring grow from children to adults, they often transition to their own distinct partisan identity, sometimes even in opposition to that of their parents (Mattei and Niemi 1991; Niemi and Jennings 1991). One likely independent influence on an individual's partisanship is one's more fundamental cultural orientation, which may also diverge from that of one's parents. Even when parental partisanship is passed on, it would often be fair to say that in those cases, the partisanship is but one small part of a larger cultural inheritance given by the parents.

Another relatively weak influence on political opinion is material interests, narrowly understood. Wildavsky perceived his cultural theory of preference formation to be a competitor of rational choice or economic theories, which he criticized for treating preferences and interests as "exogenous"-_"'tastes,' for which . . . there is no accounting;" culture theory, by contrast, treats preferences as "endogenous"- "the products of social relations" (Wildavsky 1987, 5-6). If individuals' cultural identities powerfully shape what they take their interests to be, we should expect interests measured by socioeconomic status or any other individual characteristic independent of culture to have little explanatory power once cultural worldviews are taken into account. 
The one thing our model does treat as exogenous - for expository purposes - is culture itself. In our model, we venture to identify no determinants of individuals' cultural identities (other than the limited forms of identity delineated by group-grid). Aside from the claim that the group-grid ways of life were likely to be held in equipoise by forces of social selection (Thompson et al. 1990), Wildavsky had little to say about the origins of these types or of variance in cultural disposition across individuals. ${ }^{1}$

WHM does imply, however, that individual differences in cultural identity cannot be the product of certain particular influences. One of these is conventional liberal/conservative ideology. Wildavsky himself was adamant that the political dispositions associated with the group-grid ways of life defy a simple, twodimensional, left-right scheme (Wildavsky 1991), which he described as "beset with contradictions" (1987, 11). Indeed, the viability of his theory demands as much. For if it could be shown that conventional conservative/liberal ideology is what moves individuals to sort themselves into the cultural ways of life featured by group-grid, then it would be incoherent to suggest that immersion in those ways of life compensates for the inability of most citizens to engage in ideological reasoning. Accordingly, were it shown that individuals' cultural identities lose their explanatory power once ideology is taken into account - that any connection between culture and political opinions is essentially spurious-Wildavsky's theory would be decisively refuted.

The same would be true were it to be shown that cultural identity is explained by demographic or other variables that might be understood as reasonable proxies for individuals' economic interests. For then, far from interests being endogenous to culture, as Wildavsky posited, culture would be shown to be an artifact of material interest. Accordingly, WHM implies that culture should suffer little if any loss of explanatory power once variables of that sort are taken into account.

\section{THE CURRENT STUDY}

The cultural preference-formation model we have suggested - WHM — admits of testing by a variety of means. We use the methodology predominant in empirical investigations of the cultural theory of risk perception. These studies use opinion surveys to assess the relationship between risk perceptions and "cultural worldviews," the values associated with the group-grid ways of life (e.g., Dake and Wildavsky 1991; Jenkins-Smith and Smith 1994; Marris et al. 1998; Peters and Slovic 1996). The power of worldviews

\footnotetext{
${ }^{1}$ One intriguing possibility is that dispositions toward hierarchy, egalitarianism, individualism, and solidarism are genetic depositions within individuals. This conclusion is supported by recent studies suggesting that political predispositions generally might have a strong genetic component (Alford et al. 2005).
} 
to explain variance in risk perception is thought to furnish strong evidence that cultural ways of life permeate the cognitive and social processes by which individuals ascertain risk. Similarly, a finding that worldviews predict political opinions, controlling for other potential influences, would support the inference that culture orients the more proximate heuristic mechanisms of mass opinion formation, as depicted in WHM. We thus constructed a survey instrument that allowed us to assess the relative impact of cultural worldviews and pertinent alternative influences on a variety of policy-related attitudes.

\section{Predictiveness of Cultural Worldviews}

Tested in this fashion, WHM entails a number of hypotheses, the first of which reads as follows: Cultural worldviews will predict individuals’ positions on policy. This general hypothesis yields eight specific predictions - one for each of the two cultural dimensions across four different policy domains. First, we included measures of attitudes on environmental protection, an issue of particular concern to Douglas and Wildavsky (1982). Following their work, we anticipated that the more hierarchical (high grid) and individualistic (low group) individuals were in their orientation, the more they would oppose environmental regulation, and the more egalitarian (low grid) and collectivist (high group) the more they would support it.

Second, we predicted that hierarchical and individualistic worldviews would cohere with opposition to gun control, consistent with the association of guns with hierarchical social roles (hunter, protector, father) and with hierarchical and individualistic virtues (courage, honor, chivalry, self-reliance, prowess). Egalitarianism and collectivism, we anticipated, would cohere with support for gun control because of the association of guns with patriarchy and racism, and with distrust and indifference to the well-being of strangers (Kahan and Braman 2003).

Third, we predicted that cultural worldviews would influence positions on the death penalty. Previous research suggests that variance in death penalty attitudes can be attributed to symbolic political conflict (Ellsworth and Ross 1983; Tyler and Weber 1982; Stolz 1983). We hypothesized that the groupgrid" worldviews would capture these divisions. Persons disposed to hierarchy as well as those disposed toward individualism, we anticipated, would support the death penalty, the former because they see capital punishment as symbolic of deference to authority and opposition to social deviance, and the latter because they see it as symbolic of the law's commitment to individual responsibility. Persons disposed to egalitarianism and those disposed toward collectivism, we predicted, would oppose capital punishment, the 
former because of its association with racial inequality, and the latter because of its perceived denigration of society's responsibility to ameliorate the social conditions that generate crime (Kahan 1999).

Finally, environmental regulation, gun control, and capital punishment are all policy issues on which we expected dispositions toward hierarchy and individualism to point in the same directions, but we also included a policy item on which we anticipated the two would diverge. On the issue gay marriage, we hypothesized that hierarchists and solidarists would go one way, and egalitarians and individualists another. Wildavsky (1987) himself speculated that hierarchists would take a dim view of gays, whom they would associated with transgression of traditional societal norms. This sensibility, we reasoned, should incline hierarchists to oppose the governmental legitimation of homosexuality implicit in recognizing gay marriage. By the same token, because tolerance for homosexuality symbolizes "antiestablishment" tendencies and "reduc[tion] [of] differences among people" (Wildavsky 1987, 15), persons of egalitarian and individualist dispositions should be expected to favor this change in law.

\section{Culture vs. Socio-Demographics}

Our second hypothesis holds that cultural worldviews will better explain political opinions than demographic variables. WHM treats individuals' perceptions of their material interests as endogenous to culture. Accordingly, we predicted that controlling for demographic variables - which we treat as rough proxies of material interests - would not substantially erode the explanatory power of cultural worldviews. As argued earlier, our model maintains that cultural identities shape what individuals take their interests to be, apart from their socioeconomic status or other demographic or individual characteristics. Disentangling of the connections between these characteristics and cultural orientations is beyond the scope of the present paper, but at this juncture, we maintain simply that cultural orientations are a strong predictor of policy attitudes independent of demographics, whereas the latter variables lose much of their predictive strength when controlling for cultural orientations.

\section{Culture vs. Political Self-Identification}

Third, our model predicts that cultural worldviews will better explain political opinions than conventional liberal/conservative and partisan self-identifications. The explanatory superiority of culture over these conventional measures of predispositions follows from the central claim that culture enables the formation of political opinions by individuals who lack the time, capacity, or interest necessary to derive

policies form ideological abstractions. Accordingly we predicted that cultural orientation would explain more variance in policy attitudes than does liberal-conservative self-identification or partisanship, and that taking 
account of the latter would not substantially detract from the explanatory power of the former. Even more important, we hypothesized that cultural worldviews, but not the conventional self-identifications, would explain significant variance in policy attitudes even at low levels of political knowledge. Finally, because WHM conceives of political self-identification as one means of expressing cultural leanings, we predicted that cultural worldviews would themselves explain the tendency of individuals, including relatively unsophisticated ones, to identify themselves as liberals or conservatives or as members of the Republican and Democratic parties.

\section{DATA AND MEASURES}

To test each of these hypotheses, a random telephone survey sample of 1843 adult United States residents was collected from June-September 2004, including an oversample of 242 African-American respondents. Excluding the oversample, ${ }^{2} 56 \%$ of the national sample was female, and $77 \%$ of respondents were White. The median age was 49 , and the median annual household income range was $\$ 40-\$ 50,000$.

A conservative specification of the survey response rate was $42 \%$, with a cooperation rate of $59 \%$, which means that roughly six-in-ten of those identified as eligible respondents completed the survey. ${ }^{3}$ Overall, with a two-tailed significance criterion of .05, the full sample had sufficient statistical power to detect very small effect sizes $(r<.10)$; for the smallest subsample presented herein $(\mathrm{n}=357)$, there was adequate power to detect effects at $r \geq .15$ (Cohen 1988).

Respondents completed a telephone survey instrument that began with a battery of cultural orientation questions, followed by a mix of policy items, ${ }^{4}$ with the final set of questions addressing political knowledge, political self-identification, and demographics. Each of the items used in this study are described in the text below and in the Appendix.

\footnotetext{
2 The oversample is only included in analyses when ethnicity is a variable in an analysis. All descriptive statistics are for the national random sample.

${ }^{3}$ We used the American Association for Public Opinion Research response rate version RR3 and cooperation rate COOP1. RR3 estimates what proportion of contacts with unknown dispositions were, in fact, eligible for the survey. Full specification of these formulas is available at http://www.aapor.org/pdfs/newstandarddefinitions.pdf, and the estimation procedures are available on request from Northwest Survey \& Data Services.

${ }^{4} \mathrm{We}$ also collected additional data to test more specific hypotheses about attitudes toward the risks of gun ownership. Items omitted from this article include ones relating to gun ownership, hunting, fear of assault, and other gun and crimerelated experiences and attitudes.
} 


\section{Cultural Orientation}

Through the phone survey method, one's cultural orientation can be ascertained by asking questions that assess a combination of core beliefs and linguistic preferences. Previous research had created survey items for this purpose (Dake 1991; Jenkins-Smith and Smith 1994), but an effort was made to create a new set of items that would both exhibit better scale reliability and effectively distinguish the different dimensions of cultural orientation in factor analysis.

The basic approach was to ask respondents if they strongly agreed, agreed, disagreed, or strongly disagreed with each of a series of statements. This simultaneously measured a respondent's identification with the values and language embedded in each statement. After extensive pretesting, a final set of 30 items was included in the questionnaire were used to create scales measuring the two dimensions of cultural worldview-egalitarian-hierarchy (Hierarchy, alpha $=.80, M=2.38, S D=.47$ ) and solidarism-individualism (Individualism, alpha $=.78, M=2.70, S D=.33) .{ }^{5}$ Item wording appears in the Appendix.

\section{Partisan and Liberal-Conservative Self-Identification}

To assess partisan identity, respondents were asked, "Generally speaking, do you usually think of yourself as a Republican, a Democrat, an Independent, or something else?" Those who self-identified with a major party were then asked, "Would you call yourself a strong [Republican/Democrat] or not very strong?" Respondents were then arrayed on a five-point GOP (Republican) scale ranging from one ("Strong Democrat") to five ("Strong Republican") $(M=3.00 ; S D=1.31)$.

The standard item was also used for liberal-conservative self-labeling: "When it comes to politics, do you usually think of yourself as extremely liberal, liberal, slightly liberal, moderate or middle of the road, slightly conservative, conservative, extremely conservative, or have you not thought much about this?" A seven-point Conservative scale was created, with seven denoting the "extremely conservative" selfidentification $(M=4.33 ; S D=1.68)$.

\footnotetext{
${ }^{5}$ All analyses were conducted in SPSS 12. However, we avoided use of SPSS's missing data options (von Hippel, 2004). Instead, missing data were imputed through multiple imputation with Stata using the MICE (multivariate imputation by chained equations) module (Royston, 2004). Analyses of the resulting data sets were combined and analyzed based on the formulae presented in King et al. (2001) and Rubin (1987).
} 


\section{Political Expertise}

Objective knowledge of the political process, parties, and government institutions is likely the most common measure of expertise (Delli Carpini and Keeter 1996; Zaller 1992), and a short set of four-items was used to distinguish lower from higher levels of political expertise. Following the advice of Mondak (2001), respondents were encouraged to make a guess when unsure of their answer to reduce error due to individual differences in willingness to guess when unsure. Between $67 \%$ and $42 \%$ correctly answered each question, and after recoding the items as dichotomies (incorrect/correct), the average inter-item correlation was .21. Knowledge scores ranged from 0 to 4 correct answers $(M=2.32 ; S D=1.21)$.

\section{Policy Attitudes}

As explained, the survey included an array of policy attitudes. Responses for each item were recorded using the same agree/disagree scale described earlier, and whenever possible, similar items were combined to form scales. Gun Control is a very reliable five-item index (alpha $=.82, M=2.71, S D=.64$ ), and Environment is a reliable (alpha $=.71, M=3.07, S D=.63$ ) index measuring the perceived level of threat to the environment from nuclear power plants, global warming, and pollution generally. One-item measures captured positions on the death penalty (Death Penalty, $M=2.70, S D=.89$ ), and legalizing gay/lesbian marriage (Gay Marriage, $M=2.23, S D=1.08){ }^{6}$

\section{Socio-Demographics}

Standard items were used to measure demographic variables, and all question wordings are provided in the Appendix. Ethnicity was recoded into four categories to create two dummy-variables: White $(n=$ 1229) and African-American $(n=409)$, with the remainder set including 205 respondents. Religion was recoded into two dummy variables: Protestant $(n=658)$ and Catholic $(n=349)$, with a remainder of 594 people. Rural Childhood (population density of childhood community) and Rural Adult (population density of adult community) were recoded into two three-point scales: 1 = grew up/currently reside in rural area; $2=$ small town/suburb; and 3 = city. Education was recoded into a five-point scale: $1=$ less than high school diploma; 2 = high school graduate; 3 = some college or associates degree; 4 = college graduate; $5=$ graduate

\footnotetext{
${ }^{6}$ Ideally, each scale would have had the same number of items, but the survey instrument used for this study was designed to permit additional detailed analyses of pincipally gun control (and secondarily environmental protection). Future investigations will consider a wider range of policy attitudes with equal-sized attitude scales. Gay Marriage was originally included among a set of exploratory items considered for inclusion in the egalitarian-hierarchy scale. In the end, the scale was constructed only with items that reflected only more general attitudes as opposed to specific policy positions, which as a theoretical matter we understand to be consequences of more basic cultural dispositions. Accordingly, we have used Gay Marriage as an dependent variable for purposes of analysis.
} 
or professional degree (e.g., MA, PhD, MD, JD, DDS). Income was left as an untransformed scale. (Log transformations and recodings of income had no impact on results.) Female, Age, Household Income were all measured with conventional one-item scales.

\section{RESULTS}

\section{Predictiveness of Cultural Worldviews}

To test the predictiveness of cultural worldviews, the worldview scales were entered as independent variables in a regression equation for each policy attitude. As shown in Table 1, the standardized coefficient for each scales was significant $(p<.01)$ in the expected direction, including correlations in opposite directions for Hierarchy and Individualism with respect to gay marriage.

Considered in tandem, the cultural worldview variables displayed large total effect sizes (Cohen 1988), as reflected in $\mathrm{R}^{2}$ s associated with the various regression equations. These findings support the hypothesis that egalitarianism-hierarchy ("grid," within Douglas's scheme) and individualism-solidarism ("group") are two substantially important and distinct influences on the political opinions of the American public.

\section{Culture vs. Demographics}

The second hypothesis posited that demographic characteristics would have only weak associations with policy attitudes after accounting for cultural worldviews. A second set of regression equations were conducted to test this claim, and Table 2 shows results consistent with the hypothesis.

The bottom of Table 2 shows the change in $\mathrm{R}^{2}$ when the two sets of variables were entered in separate steps: Cultural worldviews explained substantially more variance than did demographic characteristics, which themselves had at most small effects (Cohen 1988) on each policy attitude after taking cultural worldviews into account. In addition, in every case, the significant impact of the respective worldview variables survived the addition of demographic variables. This result corroborates the conclusion that the impact of cultural worldviews is not an artifact of their correspondence with demographic characteristics understood as proxies of material self-interest.

Indeed, it was the explanatory power of various demographic variables that proved sensitive to fuller specification of the regression models. When the same regression shown in Table 2 was run without cultural orientation, the demographic variables had significant associates with the policy attitudes; the final model in Table 2 removed many of those associations. For example, education, which exerted a significant impact 
with respect to capital punishment $(b=-.13, p<.001)$, gun control $(b=.15, p<.001)$, and gay marriage $(b=$ $.13, p<.001)$ in the model without cultural orientation, lost its significance after the addition of the cultural variables. ${ }^{7}$ Similarly, black had a significant association with capital punishment $(b=-.10, p<.01)$ but became non-significant in Table 2. These results, combined with the lack of significant explanatory power for household income across three of the four policy issues, conform to Wildavsky's conjecture that interests are endogenous to cultural worldviews and not a product of material conditions independent of culture.

\section{Culture vs. Political Self-Identification}

A final set of analyses tested the hypothesis that cultural worldviews better explain policy attitudes than conventional measures of liberal/conservative self-identification and partisanship. Table 3 reports the results of a series of regressions in which cultural and political self-identifications were treated as independent variables and policy attitudes as dependent variables.

The bottom of Table 3 shows the change in $\mathrm{R}^{2}$ when the two sets of variables were added in separate steps, and this shows that the unique explanatory power of the cultural worldview variables dwarfed that of the political variables. The change in $\mathrm{R}^{2}$ was three times larger for the cultural variables with respect to gay marriage: The political identity variables added .04 to $\mathrm{R}^{2}$ when entered after two cultural variables, whereas the culture scales added .12 to $\mathrm{R}^{2}$ when entered after the political scales. The unique contribution of culture was four times larger than that of political identity with respect to environmental hazards, and overwhelmingly larger with respect to gun control and the death penalty.

Entered into the regression after the cultural worldview scales, liberal/conservative self-identification and partisanship added no explanatory power to a model on capital punishment attitudes. Each political identity variable had independent and significant explanatory power with respect to each policy attitude in limited regression models in which they were the sole predictors; however, once the cultural worldview variables were added to the model, as in Table 4, liberal/conservative self-identification lacked any significant independent effect with respect to every policy attitude except gay marriage, and partisanship lacked significant independent effects with respect to gay marriage and capital punishment.

Additional analyses examined whether the respective explanatory power of the cultural worldview variables and the political identity variables was conditional on political sophistication. As expected, the

\footnotetext{
${ }^{7}$ Our sample had sufficient statistical power to detect small effect sizes (e.g., $\left.r=.10\right)$ at a significance criterion of .01 in all anticipated multivariate regression analyses (Cohen 1988). Accordingly, nonsignificance findings in these analyses are not properly attributed to Type II error.
} 
power of liberal/conservative self-identification significantly interacted with political knowledge for every single policy attitude, and GOP significantly interacted with political knowledge with respect to gun control attitudes and environmental attitudes. However, contrary to expectations, Hierarchy interacted with knowledge for all four policy attitudes, though Individualism significantly interacted with political knowledge only with respect to gun control attitudes. ${ }^{8}$

To determine the degree to which the explanatory power of the culture and political selfidentification variables were dependent on political sophistication, we split our sample into three politicalsophistication groups depending on how many political knowledge questions they answered correctly: all incorrect or one correct answer was coded as "Low," with two-to-three correct as "Medium," and four-outof-four as "High." Parallel regressions were performed using the political and the cultural variables, respectively, as predictors of policy attitudes within each group. As shown in Table 4, with respect to the policy attitudes for which there was a political sophistication interaction, both cultural variables significantly explained policy attitudes at low as well as medium and high levels of knowledge. ${ }^{9}$ Liberal/conservative selfidentification, by contrast, significantly predicted Low Knowledge respondents' positions only on gay marriage, and GOP predicted only environmental and capital punishment attitudes among Low Knowledge respondents. Although we had anticipated that the power of cultural worldviews to explain policy attitudes would not be conditional on political sophistication, we did find, consistent with Wildavsky's theory and our hypotheses, that the cultural worldview variables have substantially more explanatory power among politically unsophisticated respondents than did liberal/conservative self-identification and partisanship.

Finally, we hypothesized that the disposition of individuals to identify themselves as liberals or conservatives or as Republicans or Democrats could be explained by respondents' cultural worldviews, and the results in Table 5 support this prediction. As shown at the bottom of Table 5, for both liberalconservative self-identification and GOP, the cultural variables exerted significant and large (Cohen 1988) effects even when entered after a battery of demographic variables (change in $\mathrm{R}^{2}=.22$ for Conservative, .17

\footnotetext{
${ }^{8}$ Interaction effects were measured in parallel moderated multivariate regression analyses in which the dependent variables were the various policy attitudes and the independent variables were either the political or the cultural variables, political knowledge, and the product of the relevant political or cultural variable and political knowledge (see generally Aiken et al. 1991).

${ }^{9}$ The lone exception was that individualism did not have a significant independent effect on environmental attitudes for respondents in the Low Knowledge group $(b=-.04)$.
} 
for GOP). By contrast, demographics add relatively little to the $\mathrm{R}^{2}$ when entered after culture (.02 and .08 , respectively).

Remarkably, all the explanatory power of culture was supplied by the egalitarian-hierarchy dimension of cultural worldview. Solidarism-individualism had no unique impact on either ideological selfidentification or partisanship, and its removal from the regression models reduced $\mathrm{R}^{2}$ by less than .01 in both. This finding supports Wildavsky's position that group-grid's two-dimensional typology captures an element of mass political orientation that evades conventional one-dimensional, left-right typologies. We consider the implications of this finding in the Discussion.

Also noteworthy was the impact of cultural worldviews on the explanatory power of Female. Whereas Female otherwise predicted identification with the Democratic party (unsurprisingly), taking cultural worldviews into account deprived Female of any significant impact. The "gender gap" in partisan politics (Box-Steffensmeier et al. 2004) may an artifact of a cultural divide between men and women along the egalitarian-hierarchy dimension of worldview.

We also conducted analyses to determine whether the explanatory power of cultural worldview (Hierarchy, in particular) was conditional on political sophistication. There was, indeed, a significant interaction between Knowledge and Hierarchy with respect to both Conservative and GOP. But even at Low Knowledge and controlling for demographics, Hierarchy was significantly associated with both Conservative (change in $\mathrm{R}^{2}=.10$ ) and GOP (change in $\mathrm{R}^{2}=.06$ ).

\section{DISCUSSION}

\section{The Wildavsky Heuristic Model of Political Opinion}

This study provides considerable support for the Wildavsky Heuristic Model (WHM). Consistent with the first two general hypotheses, cultural worldviews strongly predicted a wide range of policy attitudes independent of demographic variables. This result is consistent with Wildavsky's conjecture that not only political preferences but also preference-formation heuristics are endogenous to cultural ways of life. It is well-established that ordinary citizens — particularly ones of modest or low political sophistication — rely on a variety of heuristics, including affect, various forms of information filtering, and availability, to form judgments on complicated political matters. The finding that these judgments are arrayed in patterns consistent with group-grid worldviews is most readily explained if we assume, with Wildavsky, that cultural outlooks themselves interact with and ultimately determine the valance of these various heuristics. 


\section{The Cultural Origins of Political Self-Identification and Partisanship}

Results also furnished strong evidence supporting the third hypothesis by showing that cultural worldviews better predict political opinions that does conventional conservative/liberal self-identification or partisanship. It would have been a shocking finding indeed were this not the case, for it has long been known that the vast majority of American citizens do not hold deep or coherent ideological views (Converse 1964). Consistently with this well-established insight, our study found that liberal/conservative self-identification lacked the power to predict political opinions for persons of low levels of sophistication for three of the four policy attitudes examined. By contrast, cultural worldviews generally were able to predict positions of lowsophisticated individuals on all policy issues, confirming Wildavsky's assertion that their immersion in cultural ways of life endows individuals with materials and aptitudes that substitute for more intensive engagement in political matters.

Contrary to our expectations, we did find that the predictive power of cultural worldviews, like that of liberal-conservative self-identification and partisanship, interacts with political sophistication to some degree. Although cultural worldviews explain variance in political positions at all levels of sophistication, it has even greater explanatory power for relatively sophisticated individuals than it does for their less sophisticated counterparts.

This finding supports a modified conceptualization of WHM. On this view, cultural worldview, on the one hand, and liberal-conservative self-identification and partisanship, on the other, are treated as alternative political-opinion orienters of varying strength within a population of individuals whose politicalreasoning capacities are heterogeneous. Liberal/conservative self-identification and partisanship are relatively weak orienters: Only persons whose political reasoning capacities are highly developed are able to receive and translate the organizing signal that these influences exert on opinion. Hierarchy-egalitarianism and individualism-solidarism, in contrast, are relatively strong orienters: Persons of high political capacity might have the clearest understandings of their policy implications, but cultural worldviews orient even lowcapacity individuals, who are guided by them (and only them) in forming policy judgments.

More generally, our study suggests that cultural orientation can explain and clarify much of the previously documented association between attitudes, partisanship, and liberal-conservative self-labeling. Typically, liberal-conservative self-labeling and partisanship are either used interchangeably with or treated as joint indicators of "ideology” (e.g., Jacoby 1995; Zaller 1992). This usage, though, seems unduly imprecise and creates unnecessary analytical difficulties for theories — such as Zaller's RAS model — that 
seek to explain how "ideological predispositions" can be usefully integrated into an account of how persons too unsophisticated to reason ideologically form political opinions.

Consistent with WHM, our data suggests that all three of these concepts should be treated as distinct phenomena. We found, consistent with Converse (1964), that ideological thinking is remarkably rare in the general public. If it is a useful tool for understanding public opinion, it is only because many intellectuals, elite party activists, and elected officials (individuals of high political sophistication) do hold ideologies and use them to define the policy platforms of their respective political parties. Thus, ideology explains the coherence of partisan cues, but it would be a mistake to then characterize any aspect of the mass public as ideological in this same sense. ${ }^{10}$

Nevertheless, we did find that cultural worldview_or at least the egalitarian-hierarchy dimension of it-predict liberal-conservative self-identification and partisanship for individuals even of low levels of political sophistication. Since we know those individuals are not ideological in any deep sense, our data fortifies Jacoby's $(2002,135)$ doubts about the appropriateness of treating "liberal-conservative identification [as] truly an ideology in the first place."

If not ideology, what is the liberal-conservative self-identification? The common form of this question is as follows: "We hear a lot of talk these days about liberals and conservatives. I'm going to show you a seven-point scale on which the political views that people might hold are arranged from extremely liberal (point 1) to extremely conservative (point 7). Where would you place yourself on this scale?" We interpret this exchange between the interviewer and the interviewee as a semi-public conversation in which respondents are asked to express their level of comfort with or affinity for two potent words-perhaps even "keywords"-in American politics (Hart et al. 2004). The special political/cultural significance of invoking "liberal" and "conservative" makes the words themselves significant expressions of one's partisanship and cultural orientation. In a sense, this is simply a more literal variant of the symbolic politics interpretation of liberalism-conservatism (Sears 1993); the difference is that we more clearly designate "liberal" and "conservative" as linguistic symbols and look deeper-to cultural orientations-when conceptualizing the underlying predispositions. Thus, based on our data, we suggest that one's willingness to self-label as liberal

\footnotetext{
${ }^{10}$ It would also be a mistake to view cultural worldview as equivalent to ideology. We make clear and useful conceptual distinctions between the mass public's cultural orientations and the ideological structure of elite beliefs, and it would only confuse matters to conflate the two. Some scholars do speak of cultural values in the language of ideology (van Dijk 1998), but we do not believe it is fruitful to do so in the context of explaining public opinion because ideology already has a useful and specific meaning for political elites.
} 
or conservative is merely an expression of one's linguistic preferences resulting from primarily cultural orientations.

In any case, our results suggest that the systematic measurement of solidarism-individualism and egalitarianism-hierarchy can increase our ability to predict and explain the origins of mass public opinion. Thus, we differ with Jacoby $(2002,125)$, when he argues that "a large segment of the public" have policy attitudes that "tend to be based upon criteria that are either specific to each particular issue . . or grounded in longstanding, and easily visible partisan ties (i.e., party identification)." Solidarism-individualism and egalitarianism-hierarchy reveal highly general coherence in what Jacoby and others see as either issuespecific variation or noise.

\section{Group Grid vs. Left-Right: Two Dimensions Are Better than One}

The "group" and "grid" dimensions of the Douglas typology are not of a piece in their impact on political self-labeling. Both explain differences in various policy attitudes, but only hierarchy-egalitarianism ("grid") predicts conservative-liberal self-identification and partisanship. In other words, the force that solidarism-individualism ("group") exerts in organizing mass opinion defies conventional ideological categories. This finding coheres with Wildavsky's emphatic dissatisfaction with a one-dimensional, left-right conception of political ideology.

Treating "left versus right" as the primary explanation, Wildavsky (1987) argued, generates an account of American politics "beset with contradictions"; if "liberal . . . designates a tendency toward greater use of central government" and "conservative ... a disposition against central government" (11), then why do conservatives so readily embrace and liberals so firmly resist regulation of individual sexual behavior (including abortion and homosexuality), the criminalization of drug use, and highly discretionary police investigatory power? How, in any case, can these opposing attitudes toward government be reconciled with the proposition that conservatives "respect authority" while liberals "distrust" it (Wildavsky, 1987, 12)? Alternatively, if these labels describe "innate tendencies toward change" (conservatives against, liberals in favor) (Ibid.), then why in recent times have conservative Republicans so aggressively assaulted and liberal Democrats so fervently defended an array of governmental programs and regulatory institutions instituted well over half a century ago? In his 1987 article and elsewhere (Wildavsky 1991), Wildavsky demonstrated that the conventional (and mutually inconsistent) associations of "left" and "right" on issues of governmental intervention, authority, and change could not explain shifts within "liberal" and "conservative" political 
parties on all of these positions over time. "A division of the world into left and right that is equally inapplicable to the past and to the present deserves to be discarded" (1987, 11-12).

In its place, Wildavsky, of course, suggested the two-dimensional typology of dispositions delineated by group-grid. Hierarchists, egalitarians, individualists and solidarists would each variously support or oppose central government power, support or criticize authority, and demand or resist change, he maintained, depending on what stance advanced their preferred way of life in any given circumstance.

Pivotal within Wildavsky's reconfigured ideological map was the fluidity associated with individualist-solidarism dimension of group-grid. Egalitarians and hierarchists could be expected consistently to square off against one another on whether governmental power should be used to attack or bolster various forms of social stratification. Hierarchs, he wrote, would support "giving government the right to intervene in matters of personal morality" (Wildavsky 1987, 11), whereas egalitarians would predictably oppose such policies as forms of "intervention in social life [designed] to maintain" status inequality. Egalitarians, in contrast, would predictably "support intervention in the economy to reduce economic differences"- $\mathrm{a}$ use of governmental authority opposed (at least most of the times) by hierarchists as impugning the competence and threatening the prerogatives of social elites (Wildavsky 1987, 11; see also Douglas and Wildavsky 1982). ${ }^{11}$ Individualists, Wildavsky argued, would variously align with one side or the other in these disputes: with hierarchs in opposing economic regulations that constrain the autonomy of private ordering in the market place; but with egalitarians in opposing coercive enforcement of dominant norms - both as abridgments of personal choice in moral matters and as potential constraints on individual initiative and exchange. The tipping effect associated with the disposition of individualists to align opportunistically with either hierarchs or egalitarians in their consistent battle with one another generates a "triangular" quality to American political conflict that consistently defies the "dichotomous" characterizations associated with left-right schemes (Wildavsky 1987, 11; see also Wildavsky 1991).

Our results corroborate Wildavsky’s view. Hierarchy-egalitarianism predicts ideological selflabeling and partisanship because this dimension of group-grid captures reasonably well the ambivalence that "conservatives" and "liberals," Republicans and Democrats have toward government power, authority, and

\footnotetext{
${ }^{11}$ Wildavsky recognized, however, that it was conceivable that redistributive programs might actually be viewed as congenial to egalitarians and hierarchists alike under some circumstances $(1987$, p. 11). This theme is systematically developed in Teles (1996), who argues that egalitarians and hierarchs for a long period of American history joined forces against individualists in support of social welfare programs, the former to promote economic equality and the latter to resist market pressures that were seen as threatening to force women out of the home and into commerce.
} 
change. But the influence of solidarism-individualism on these matters confounds the generalizations associated with left-right categories. Accordingly, how individuals' outlooks measure up along the group dimension will not predictably make them identify as either "conservative" or "liberal," Republican or Democrat. Indeed, it seems plausible to think that the mismatch between the group dimension of group-grid and conventional left-right categories accounts for much of the failure of the latter to explain mass political opinion. And it is exactly the power of group-grid to capture this distinctive political sensibility that allows it to disclose the order in mass public opinion that dominant theories have found lacking.

\section{Reconceptualizing “Cultural Politics”}

Common and professional understandings tend to clash on the cultural complexion of American politics. Popular and journalistic accounts emphasizes the centrality of cultural conflict (e.g., Hunter 1991; Lakoff 2002). "Culture," one prominent proponent of this view asserts, "outweighs economics as a matter of public concern" (Frank 2004, 6). Indeed, it was by deftly aligning themselves with the cultural values of lower middle class Americans on matters like gay marriage, abortion, and capital punishment that Republicans managed to win the support of this constituency notwithstanding the party's support for economic policies that are clearly inimical to the interests of these voters. Political scientists tend to scoff at this view (Fiorina et al. 2004). The "culture war" position not only defies the decidedly non-ideological disposition of the all but the most politically sophisticated citizens, but also contravenes more sophisticated measures that show that, contrary to popular punditry, material issues mattered more than "moral values" even in the 2004 election. $^{12}$

WHM and the data we have presented in support of it suggest a distinctive alternative to both the popular and professional perspectives. Our findings show that cultural values clearly do generate major divisions of opinion on a range of issues — not just among partisans or elites but also among moderate citizens of meager political sophistication. Academic skeptics of the existence of culture conflict within the American electorate rely heavily on evidence that the vast majority of citizens are not strongly ideological in their opinions. But that work shows only that the ideologies conventionally measured are a bad proxy for cultural worldviews, not that cultural worldviews are politically inert.

\footnotetext{
${ }^{12}$ Many news media outlets identified "moral values" as the primary concern of voters in the 2004 election. However, a Pew Research Center poll of 2004 voters found that the disposition of voters to identify moral values as the most important factor in their decision was extremely sensitive to question wording, and that in fact $57 \%$ of voters identified either "Iraq" (22\%), "Economy/Jobs" (21\%), or "Terrorism" (14\%) as the most important when those choices were offered as alternatives to "moral values" (27\%). See http://people-press.org/-reports/-dis-play.-php3?-ReportID=233.
} 
Nevertheless, WHM does little to vindicate the hyperbole associated with the popular "cultural war" position. That view sees American politics as dominated by illiberal jockeying among opposing cultural groups bent on capturing the expressive capital of law (Hunter 1991). Nothing in WHM entails that picture of American politics. Instead, Wildavsky's view of the endogeneity of preferences and preference-formation heuristics to culture explains how citizens whose only concern is their material well-being, narrowly understood, are still likely to array themselves into opposing cultural factions on political maters. Citizens aren't in a position to figure out for themselves what economic, crime-control, environmental or national security policies advance their material interests. Accordingly, they rely on various heuristics, including their affective responses to policies and candidates (Sniderman et al. 1991), and the perceived knowledge and interests of various policy advocates (Lupia 2002). But what determines which policies and persons they like? Or which advocates they perceive as knowledgeable and as sharing their interests? Wildavsky's answers, which are supported by our data, are the cultural resonances of those policies, and cultural allegiances of those candidates and advocates.

In sum, cultural values don't motivate mass political opinion, as popular commentators image. They merely orient it through a complex set of interrelated social and cognitive mechanisms. The paradoxical result is the cultural polarization of even relatively nonpartisan and tolerant citizens whose most pressing political concern is to identify which policies and which party will best help them make ends meet.

\section{Advancing the Cultural Approach: Measurement, Experimentation, and Integration}

If the cultural account is to move forward, it will be necessary to further refine the measurement of its core concepts. One important reason that the liberal-conservative operationalization of mass ideology remains popular among researchers is it is easy to use. In critiquing this approach, Maddox et al. $(1984,30)$ acknowledge that "conceptualization, question and scale construction, statistical analysis, and even graphic representation are all simplified when working with a single dimension." Moving to the cultural orientation approach certainly adds a degree of difficulty to each step of the process, and although we are confident the gain in validity and explanation is well worth the cost in parsimony, it is vital that the operationalization of cultural orientations be as straightforward and efficient as possible.

Unfortunately, precise measurement of cultural orientation is challenging. One of the difficulties in measuring cultural values is that historical context matters. Items that effectively distinguish between values, such as egalitarianism and hierarchy, can lose their potency as a social consensus emerges, as has happened 
with the question of whether it is appropriate for a married woman to be working if she has a husband capable of supporting her (Page and Shapiro 1992). Other items, such as those in the famous F-scale measuring authoritarian personality (Adorno et al. 1950), continue to have conceptual meaning but require wording changes to reflect changing connections between culture and language. Both challenges, though, are shared by the simple liberal-conservative self-identification item, which places the operational definition of ideology in the hands of two politically charged words.

Another challenge is to take head-on the question of values and language as distinct indicators of cultural orientation. Herein, we sidestepped the issue by acknowledging that our measures tap into both underlying values and linguistic preferences associated with the two dimensions of cultural orientation. There may emerge more sophisticated methods for disentangling these, such as eliciting responses to individual words or tapping beliefs through the implicit attitude measurement techniques (Greenwald and Banaji 1995).

These operational refinements could be applied not only to additional survey research but also to experimental investigations aimed at clarifying the social and cognitive processes whereby cultural orientation exerts its influence on people's policy attitudes. Contemporary social psychology suggests that cultural worldviews could decisively influence that process through a number of discrete mechanisms. The most likely candidate is affect (Sniderman et al. 1991), which also plays a critical role in risk perception (Slovic 2004; Finucane et al. 2000), and which is likely shaped by cultural influences. Others include cognitive dissonance avoidance, which might incline individuals to resolve contested empirical claims in a manner compatible with their cultural identities (Sherman and Cohen 2002), and biased assimilation (Lord, Ross and Leper 1979), which would induce them to credit or discredit factual information in a manner supportive of their prior, culturally grounded views. Finally there are various in-group and out-group dynamics, such as naïve realism (Robinson et al. 1995), reactive devaluation (Ross 1995, and group polarization (Sunstein 2002), which could motivate individuals to trust those who share their cultural allegiances and distrust those who do not when cultural groups disagree about risk or other factual issues relevant to policy.

Other experiments might identify influences that qualify the shaping power of cultural worldview. Deliberation, for example, might trump cultural orientation under the right circumstances. Deliberation might prove most influential when one's values "have ambivalent implications for the issue at hand" (Lindeman 2002, 205), such as the tension egalitarians might feel toward legalizing prostitution (e.g., does it empower 
women or legitimize their exploitation?). Alternatively, the experience of highly consequential deliberation, such as the 2004 British Columbia Citizens' Assembly, ${ }^{13}$ might produce an intensely shared civic identity, which at least for the period of deliberation, could displace cultural orientation as individuals' primary reference group. ${ }^{14}$ In any case, it might be possible to simulate this experience to a sufficient degree and see whether common civic identity can override culturally grounded prior beliefs.

A broader challenge for the cultural approach is to reconcile different conceptions of cultural orientation. We have begun with two dimensions that are well grounded in broader cultural theory (Douglas 1970), but there are other cultural approaches that are theoretically well-developed and may permit a synthesis with WHM. Inglehart $(1989,1997)$ has famously defined culture in two dimensions - traditional versus secular-rational and survival versus self-expression. Examination of the items that represent the traditional cultural orientation (Inglehart and Baker 2000) show considerable overlap with the hierarchy dimension, though the survival dimension also overlaps with hierarchy. For instance, both scales use items affirming traditional gender roles. Moreover, neither dimension captures the essence of egalitarian, individualist, or collectivist orientations. Self-expression sounds individualistic at times, but it does not tap as powerfully into themes of personal freedom and self-determination as it does into tolerance for nontraditional lifestyle choices. Ironically, in the United States, individualism is often equated with very conventional self-expression, with the rugged cowboy being at least as famous than the rebel motorcyclist.

Another conception of core values defines them as "transituational goals" (Schwartz and Bilsky 1987) that serve deeper interests and guide both attitudes and behavior (Bardi and Schwartz 2003). Though Schwartz and his colleagues have also mapped values in two-dimensional space, their representation is a circle with pie-slices representing different value orientations. One can crudely map the Wildavsky and Douglas (1982) dimensions onto this map, but the fit is no better than with Inglehart's post-materialist theory.

Hopefully, future research can clarify the extent to which these three (and other) cultural theories intersect. They appear to be mapping the same space, and their interpretations have considerable overlap. This much is clear already: There are core values and orientations underlying people's attitudes across the

\footnotetext{
${ }^{13}$ For the official history of the Assembly and video of its proceedings, visit http://www.citizensassembly.bc.ca.

${ }^{14}$ A number of public deliberation programs have recorded the kinds of identity and attitude changes hypothesized in deliberative theory (Burkhalter et al. 2002). For examples of such emotional experiences at deliberative forums, see Melville et al. 2005, 37-39, 45-51; Charles et al. 2005, 66; Fishkin and Farrar 2005, 68-70).
} 
globe (Douglas 1970; Inglehart 1997; Schwartz and Bilsky 1987), and they can be characterized in terms of a relatively small number of dimensions. Given the strength of these findings and the relative weakness of ideology as a means of characterizing the mass public (Converse 1964), it would be a mistake to not take the cultural approach more seriously when trying to understand the origins of public opinion.

\section{CONCLUSION}

In this paper, we have focused on Aaron Wildavsky's distinctive cultural theory of politics. Popular and academic accounts tend to depict cultural politics as a relatively self-conscious struggle between the adherents of competing ethics to express their partisan ideals through highly symbolic laws. For Wildavsky, in contrast, culture exerts an orienting force for democratic citizens whose concerns are much more practical. Lacking the time and capacity to determine for themselves which economic, crime-control, or national security policies will best promote their well-being, ordinary citizens are instinctively guided by their cultural affiliations, which imbue policies with powerful affective connotations and invest opposing policy advocates with differential levels of credibility. Culture conflict is not the object of democratic politics; it is a byproduct of the social and psychological processes through which culturally diverse citizens apprehend their common interests.

We have suggested a model for systematizing this account, and supplied empirical evidence to support it. That evidence shows that the cultural ways of life associated with Mary Douglas's group-grid theory and featured in Wildavsky's political writings more strongly predict individuals' political attitudes than any other factor, including their race or gender, their socio-economic status, and even their selfdescribed political leanings and party affiliations. Even more important, cultural ways of life so defined explain political attitudes not just for those individuals who are relatively well versed in political matters but also for all those whose familiarity with political matters is fleeting and incomplete.

These findings do not so much subvert existing accounts of mass opinion formation as integrate them. It is well established that ordinary citizens lack the sophistication to reason ideologically. Wildavsky surmised, and our evidence corroborates, that such individuals make up for this incapacity through a cultural facility that depends on very little political expertise. This conclusion in turn links Wildavsky's theory to the myriad findings that show that individuals rely on a complex of affective and cognitive heuristics in forming political opinions. Culture, on this account, is the orienting force behind these heuristics: The readily accessible meanings it supplies, and the networks of trust that it establishes, determine what affective 
response individuals experience toward various policies, and whom they trust and defer to on contested policy matters.

In concluding his own essay, Wildavsky $(1987,17)$ called for a "research program on political culture [that] would seek to increase our understanding of how opposed visions of the good life are selected, sustained, altered, and rejected." "Such a research program," he wrote, "would enable us to test the general hypotheses that how people organize their institutions has a more powerful effect on their preferences than any rival explanation — wealth, technology, class, self-interest, tradition, you name it. The field of preference formation is open to all comers" (Wildavsky 1987, 18). We have not come close in this paper to completing such a research program. But we believe that we have taken a major step toward vindicating Wildavsky's expectation of the handsome dividends such a program would yield in enlarging our understanding of mass political opinion. 


\section{References}

Adorno, Theodor W., Else Frenkel-Brunswik, Daniel J. Levinson, and R. Nevitt Sanford. 1950. The Authoritarian Personality. New York: W. W. Norton.

Aiken, L. S., West, S. G., \& Reno, R. R. 1991. Multiple Regression : Testing and Interpreting Interactions. Newbury Park, Calif.: Sage.

Alford, J., C. Funk, and J. Hibbing 2005. “Are Political Orientations Genetically Transmitted?” American Political Science Review 99: 153-68.

Bardi, Anat, and Shalom H. Schwartz. 2003. "Values and Behavior: Strength and Structure of Relations." Personality and Social Psychology Bulletin 29: 1207-20.

Box-Steffensmeier, Janet M., Suzanna De Boef, and Tse-min Lin. 2004. "The Dynamics of the Partisan Gender Gap.” American Political Science Review 98: 515-28.

Braman, Donald, Dan Kahan, and James Grimmelman. 2005. "Modeling Facts, Culture, and Cognition in the Gun Debate." Social Justice Research 18.

Burkhalter, Stephanie, John Gastil, and Todd Kelshaw. 2002. “A Conceptual Definition and Theoretical Model of Public Deliberation in Small Face-to-Face Groups.” Communication Theory 12: 398-422.

Charles, Michelle, Harris Sokoloff, and Chris Satullo. 2005. "Electoral Deliberation and Public Journalism." In The Deliberative Democracy Handbook, ed. John Gastil and Peter Levine. San Francisco: JosseyBass, 59-67.

Cohen, Jacob. 1988. Statistical Power Analysis for the Behavioral Sciences, 2nd Edition. Hillsdale, NJ: Lawrence Erlbaum.

Converse, Philip E. 1964. "The Nature of Belief Systems in Mass Publics.” In Ideology and Discontent, ed. David E. Apter. New York: Free Press, 206-61.

Dake, Karl. 1991. "Orienting Dispositions in the Perception of Risk: An Analysis of Contemporary Worldviews and Cultural Biases.” Journal of Cross-Cultural Psychology 22: 61-82.

Dake, Karl, and Aaron Wildavsky. 1990. "Theories of Risk Perception: Who Fears What and Why?" Deadalus (Spring): 41-60. 
Delli Carpini, Michael X., and Scott Keeter. 1996. What Americans Know and Why It Matters. New Haven, CT: Yale University Press.

DiMaggio, P., John Evans, and Bethany Bryson. 1996. "Have Americans' Social Attitudes Become More Polarized?" American Journal of Sociology 102: 690-755.

Douglas, Mary. 1970. Natural Symbols. New York: Pantheon.

Douglas, Mary. 1999. Implicit meanings: Essays in anthropology. 2nd ed. New York: Routledge.

Douglas, Mary, and Aaron B. Wildavsky. 1982. Risk and culture : An essay on the selection of technical and environmental dangers. Berkeley: University of California Press.

Eagly, Alice H., and Shelly Chaiken. 1993. The Psychology of Attitudes. Fort Worth, TX: Harcourt Brace Jovanovich.

Ellis, Richard, and Michael Thompson 1997. "Seeing Green: Cultural Biases and Environmental Preferences.” In Culture Matters: Essays in Honor of Aaron Wildavsky, ed. Aaron B. Wildavsky, Richard Ellis, and Michael Thompson. Boulder, CO: Westview Press.

Ellsworth, Phoebe C., and Lee Ross. 1983. "Public Opinion and Capital Punishment: A Close Examination of the Views of Abolitionists and Retentionists." Crime \& Delinquency 29: 116-69.

Finucane, M. L., Alhakami, A., Slovic, P., \& Johnson, S. M. (2000). "The Affect Heuristic in Judgments of Risks and Benefits.” Journal of Behavioral Decision Making 13: 1-17.

Fiorina, Morris P., Samuel J. Abrams, and Jeremy C. Pope. 2004. Culture War? The Myth of a Polarized America. New York: Longman.

Fishkin, James, and Cynthia Farrar. 2005. "Deliberative Polling: From Experiment to Community Resource." In The Deliberative Democracy Handbook, ed. John Gastil and Peter Levine. San Francisco: JosseyBass, 68-79.

Frank, Thomas. 2004. What's the Matter with Kansas? How Conservatives Won the Heart of America. New York: Metropolitan Books.

Goren, Paul. 2004. "Political Sophistication and Policy Reasoning: A Reconsideration." British Journal of Political Science 34: 589-610.

Graber, Doris 2004. "Mediated Politics and Citizenship in the Twenty-First Century." Annual Review of Psychology 55: 545-71. 
Greenwald, A. G., \& Banaji, M. R. 1995. "Implicit Social Cognition: Attitudes, Self-esteem, and Stereotypes.” Psychological Review 102: 4-27.

Gusfield, Joseph R. 1986. Symbolic crusade : Status politics and the American temperance movement. 2nd ed. Urbana: University of Illinois Press.

Hart, Roderick. P., Sharon E. Jarvis, William P. Jennings, and Deborah Smith-Howell. 2004. Political Keywords: Using Language that Uses Us. Oxford: Oxford University Press.

Herrera, Richard. 1997. "Understanding the Language of Politics: A Study of Elites and Masses.” Political Science Quarterly, 111: 619-637.

Hetherington, Marc J. 2001. "Resurgent Mass Partisanship: The Role of Elite Polarization.” American Political Science Review 95: 619-31.

Hunter, James D. 1991. Culture Wars: The Struggle to Define America. New York: Basic Books. Inglehart, Ronald. 1989. Culture Shift in Advanced Industrial Society. Princeton, NJ: Princeton University Press.

Inglehart, Ronald. 1997. Modernization and Postmodernization. Princeton, NJ: Princeton University Press. Inglehart, Ronald, and W. E. Baker. "Modernization, Cultural Change, and the Persistence of Traditional Values.” American Sociological Review 65: 19-51.

Jacoby, William G. 1995. "The Structure of Ideological Thinking in the American Electorate." American Journal of Political Science 39: 314-35.

Jacoby, William G. 2002. "Liberal-Conservative Thinking in the American Electorate." Political Decision Making, Deliberation and Participation, 6: 97-147.

Jenkins-Smith, Hank C., and Walter K. Smith. 1994. "Ideology, Culture, and Risk Perception.” In Politics, Policy, and Culture, ed. D. J. Coyle and Richard J. Ellis. Boulder, CO: Westview.

Kahan, Dan M. 1999. “The Secret Ambition of Deterrence.” Harvard Law Review 113: 413-500.

Kahan, Dan M., \& Braman, Donald. 2003. "More Statistics, Less Persuasion: A Cultural Theory of Gun-risk Perceptions. University of Pennsylvania Law Review 151: 1291.

Kinder, Donald R. 1998. “Communication and opinion.” Annual Review of Political Science 1: 167-197 
Kinder, Donald R., \& Sears, David O. 1981. "Prejudice and Politics: Symbolic Racism versus Racial Threats to the Good Life.” Journal of Personality and Social Psychology 40: 414-31.

King, G., Honaker, J., Joseph, A., \& Scheve, K. 2001. “Analyzing Incomplete Political Science Data: An Alternative Algorithm for Multiple Imputation.” American Political Science Review 95, 49-69.

Kline, R. B. 2005. Principles and Practice of Structural Equation Modeling. 2nd ed. New York: Guilford Press.

Lakoff, George. 2002. Moral Politics: How Liberals and Conservatives Think. 2nd ed. Chicago: University of Chicago Press.

Lord, C. G., Ross, L., \& Lepper, M. R. 1979. "Biased Assimilation and Attitude Polarization-Effects of Prior Theories on Subsequently Considered Evidence.” Journal of Personality and Social Psychology 37: 2098-2109.

Lupia, Arthur. 1994. "Shortcuts versus Encyclopedias: Information and Voting Behavior in California Insurance Reform Elections.” American Political Science Review 88: 63-76.

Lupia, Arthur. 2002. "Who Can Persuade Whom? Implications from the Nexus of Psychology and Rational Choice Theory.” In Thinking About Political Psychology, ed. James H. Kuklinski. New York: Cambridge University Press, 51-88.

Maddox, William S., Stuart A. Lilie, and David Boaz. 1984. Beyond Liberal and Conservative: Reassessing the Political Spectrum. Washington, DC: Cato Institute.

Marris, Claire, Ian H. Langford, and Timothy O'Riordan. 1998. “A Quantitative Test of the Cultural Theory of Risk Perceptions: Comparison with the Psychometric Paradigm.” Risk Analysis 18: 635-647.

Mattei, Franco, and Richard G. Niemi.1991. "Unrealized Partisans, Realized Independents, and the Intergenerational Transmission of Partisan Identification.” Journal of Politics 53: 161-74.

Melville, Keith, Taylor L. Willingham, and John R. Dedrick. 2005. "National Issues Forums: A Network of Communities Promoting Public Deliberation.” In The Deliberative Democracy Handbook, ed. John Gastil and Peter Levine. San Francisco: Jossey-Bass, 37-58.

McGraw, K. M., and Pinney, N. 1990. "The Effects of General and Domain-Specific Expertise on Political Memory and Judgment." Social Cognition 8: 9-30. 
Mondak, Jeffrey J. 2001. “Developing Valid Knowledge Scales.” American Journal of Political Science 45: 224-38.

Mutz, Diana C., and Paul S. Martin. 2001. "Facilitating Communication Across Lines of Political Difference: The Role of Mass Media.” American Political Science Review 95: 97-114.

Mutz, Diana C. 2002. “Cross-Cutting Social Networks: Testing Democratic Theory in Practice.” American Political Science Review, 96: 111-126.

Niemi, Richard G., and M. Kent Jennings. 1991. "Issues and Inheritance in the Formation of Party Identification." American Journal of Political Science 35: 970-88.

Page, Benjamin I., \& Shapiro, Robert Y. 1992. The Rational Public: Fifty Years of Trends in Americans' Policy Preferences. Chicago: University of Chicago.

Peters, Ellen., and Paul Slovic. 1996. "The role of affect and worldviews as orienting dispositions in the perception and acceptance of nuclear power.” Journal of Applied Social Psychology 26: 1427-53.

Pew Research Center for the People and the Press. 2004. 2004 Media Consumption and Believability Study. Available at: http://people-press.org/reports/display.php3?PageID=834.

Rayner, Steve. 1992. “Cultural Theory and Risk Analysis.” In Social Theories of Risk, ed. Sheldon Krimsky and Dominic Golding. Westport: Praeger.

Rhee, W., and J. N. Cappella. 1997. "The Role of Political Sophistication in Learning from News: Measuring Schema Development." Communication Research 24: 197-233.

Robinson, R. J., Keltner, D., Ward, A., \& Ross, L. 1995. “Actual versus Assumed Differences in Construal: 'Naïve Realism' in Intergroup Perception and Conflict.” Journal of Personality \& Social Psychology 68: 404-417.

Royston, P. 2004. “Multiple Imputation of Missing Values.” Stata Journal 4: 227-241.

Rubin, Donald. 1987. Multiple Imputation for Nonresponse in Surveys. New York: Wiley.

Schwartz, Shalom H., and Wolfgang Bilksy. 1987. "Toward a Universal Psychological Structure of Human Values." Journal of Personality and Social Psychology 53: 550-62.

Sears, David O. 1993. "Symbolic politics: A socio-psychological theory.” In Explorations in Political Psychology, ed. Shanto Iyengar \& William J. McGuire. Durham, NC: Duke University Press. 
Sherman, D. K., \& Cohen, G. L. 2002. “Accepting Threatening Information: Self-Affirmation and the Reduction of Defensive Biases." Current Directions in Psychological Science 11: 119-123.

Slovic, Paul. 2000. The perception of risk. London ; Sterling, VA: Earthscan Publications.

Slovic, Paul, Melissa L. Finucane, Ellen Peters, and Donald g MacGregor. 2004. "Risk as Analysis and Risk as Feelings: Some Thoughts about Affect, Reason, Risk, and Rationality." Risk Analysis 24: 311-322.

Sniderman, Paul M., Richard A. Brody, and Philip E. Tetlock. 1991. Reasoning and Choice: Explorations in Political Psychology. Cambridge: Cambridge University Press.

Stolz, B. A. (1983). "Congress and Capital Punishment: An Exercise in Symbolic Politics.” Law \& Policy Quarterly 5: 157.

Sunstein, Cass R. 2002. “The Law of Group Polarization.” Journal of Political Philosophy 10: 175-195.

Teles, Steven Michael. 1996. Whose Welfare? AFDC and Elite Politics, Studies in Government and Public Policy. Lawrence: University Press of Kansas.

Tversky, A., \& Kahneman, D. 1973. "Availability: A heuristic for judging frequency and probability." Cognitive Psychology 5: 207-32.

Tyler, Tom R., and Renee Weber. 1982. "Support for the Death Penalty: Instrumental Response to Crime, or Symbolic Attitude. Law \& Society Review 17: 21-45.

van Dijk, T. A. 1998. Ideology: A Multidisciplinary Approach. Thousand Oaks, CA: Sage. von Hippel, Paul. (2004). “Biases in SPSS 12.0 Missing Value Analysis.” American Statistician 58: 160-64. Wildavsky, Aaron B. 1987. "Choosing Preferences by Constructing Institutions: A Cultural Theory of Preference Formation.” American Political Science Review 81: 3-21.

Wildavsky, Aaron B. 1991. The Rise of Radical Egalitarianism. Lanham, MD: American University Press. Wildavsky, Aaron B., and M. Douglas. 1982. Risk and Culture: An Essay on the Selection of Technological and Environmental Dangers. Berkeley: University of California Press.

Wolfe, Alan. 1999. One Nation, After All: What Americans Really Think About God, Country, Family, Racism, Welfare, Immigration, Homosexuality, Work, The Right, The Left and Each Other. New York: Penguin.

Zaller, John R. 1992. The Nature and Origins of Mass Opinion. Cambridge: Cambridge University Press. 


\section{Appendix: Questionnaire Items}

All sets of questions (excluding political knowledge items) were preceded by the instruction, "Please tell me whether you strongly agree, agree, disagree, or strongly disagree." The full set of risk perception items (Environment, Sexual Health, Drug Danger, and Regulation Harm) were randomly ordered for each survey.

\section{Cultural World View Items}

1. Egalitarianism-Hierarchy Scale. Items beginning with "E" are reversed.

HCHEATS It seems like the criminals and welfare cheats get all the breaks, while the average citizen picks up the tab.

HEQUAL We have gone too far in pushing equal rights in this country.

HFEMININ Society as a whole has become too soft and feminine.

HREVDIS1 Nowadays it seems like there is just as much discrimination against whites as there is against blacks.

HREVDIS2 It seems like blacks, women, homosexuals and other groups don't want equal rights, they want special rights just for them.

HTRADFAM A lot of problems in our society today come from the decline in the traditional family, where the man works and the woman stays home.

HWMNRTS The women's rights movement has gone too far.

EDISCRIM Discrimination against minorities is still a very serious problem in our society.

EDIVERS It's old-fashioned and wrong to think that one culture's set of values is better than any other culture's way of seeing the world.

ERADEQ We need to dramatically reduce inequalities between the rich and the poor, whites and people of color, and men and women.

EROUGH Parents should encourage young boys to be more sensitive and less "rough and tough."

EWEALTH Our society would be better off if the distribution of wealth was more equal.

EXSEXIST We live in a sexist society that is fundamentally set up to discriminate against women.

2. Solidarism-Individualism Scale. Items beginning with "S" are reversed.

IENJOY

IFIX

IGOVWAST

IINTRFER

IMKT

INEEDS

INEEDY

IPRIVACY

IPROFIT

IPROTECT

IRESPON

ITRIES
People who are successful in business have a right to enjoy their wealth as they see fit.

If the government spent less time trying to fix everyone's problems, we' $d$ all be a lot better off.

Government regulations are almost always a waste of everyone's time and money. The government interferes far too much in our everyday lives.

Free markets - not government programs - are the best way to supply people with the things they need.

Too many people today expect society to do things for them that they should be doing for themselves.

It's a mistake to ask society to help every person in need.

The government should stop telling people how to live their lives.

Private profit is the main motive for hard work.

It's not the government's business to try to protect people from themselves.

Society works best when it lets individuals take responsibility for their own lives without telling them what to do.

Our government tries to do too many things for too many people. We should just let people take care of themselves. 
SHARM Sometimes government needs to make laws that keep people from hurting themselves.

SLIMCHOI Government should put limits on the choices individuals can make so they don't get in the way of what's good for society.

SNEEDS It's society's responsibility to make sure everyone's basic needs are met.

SPROTECT The government should do more to advance society's goals, even if that means limiting the freedom and choices of individuals.

SRELY People should be able to rely on the government for help when they need it.

Political Knowledge (randomly ordered)

Preface: Now I would like to ask you some multiple-choice questions about the political process. Please answer to the best of your knowledge, and feel free to guess even if you aren't completely sure of your answer.

1. Which party has the most members in the U.S. Senate?

2. How much of a majority is required for the U.S. Senate and House to override a presidential veto?

3. Whose responsibility is it to nominate judges to the Federal Courts?

4. How long is the term of office for a United States Senator?

Gun Control (randomly ordered)

1. I favor stronger gun control laws.

2. As long as they don't have a criminal record or a history of mental illness, any adult should be free to carry a concealed handgun in public.

3. The law should ban privately owned handguns.

4. I favor the mandatory registration of handguns.

5. There are already too many restrictions on firearms in the U.S.

\section{Death Penalty}

People convicted of murder should be subject to the death penalty.

Environment (randomly ordered)

1. Environmental pollution is a serious risk to public health in our country.

2. Global warming poses a serious danger for the future of our planet.

3. It is dangerous to live near a nuclear power plant.

\section{Gay Marriage}

A gay or lesbian couple should have just as much right to marry as any other couple.

\section{Demographics}

Rural Childhood: What kind of a community did you (primarily) grow up in? Was it a large city, a small city or town, the suburbs, or was it rural?

Rural Adult: What kind of a community do you live in? Is it a large city, a small city or town, the suburbs, or was it rural?

Age: In what year were your born?

Female: (I know this sounds silly, but I am required to ask) Are you male or female?

Ethnicity: What is your race or ethnic identity?

Religion: What is your religious preference? Is it Protestant, Catholic, Jewish, some other religion, or no religion?

Education: What is the highest level of education you have completed?

Household Income: Now please estimate your total household income for 2003. This includes income from all members of your household from all sources. I will read you a list and you may stop me at any point. [Was it (between) $\$ 10,000$ or below? $\$ 10,000$ to $\$ 20,000$ ? And continue to $\$ 80,000$ and above?] 
Table 1. A Comparison of Standardized Coefficients and $\mathbf{R}^{2}$ for Cultural Worldview Scales for Policy Attitudes

\begin{tabular}{lccc}
\hline Attitude Scale & Hierarchy $b$ & Individualism $b$ & $\mathrm{R}^{2}$ \\
\hline Environment & $-.40^{* *}$ & $-.11^{* *}$ & $.22^{* *}$ \\
Gun Control & $-.39^{* *}$ & $-.26^{* *}$ & $.30^{* *}$ \\
Death Penalty & $.35^{* *}$ & $.16^{* *}$ & $.20^{* *}$ \\
Gay Marriage & $-.60^{* *}$ & $.11^{* *}$ & $.31^{* *}$ \\
\hline
\end{tabular}

$N=1843 .{ }^{*} p<<.01,{ }^{*} p<.05$ for a two-tailed significance test. 
Table 2. Comparisons of the Standardized Regression Coefficients and Change in $\mathbf{R}^{2}$ of SocioDemographic Characteristics and Cultural Worldviews for Policy Attitudes

\begin{tabular}{|c|c|c|c|c|}
\hline Predictor & Environment & Gun Control & Death Penalty & Gay Marriage \\
\hline Hierarchy & $-.37 * *$ & $-.34 * *$ & $.32 * *$ & $-.55 * *$ \\
\hline Individualism & $-.10 * *$ & $-.24 * *$ & $.16^{* *}$ & $.10 * *$ \\
\hline Female & $.12 * *$ & $.19 * *$ & -.03 & -.01 \\
\hline Age & -.02 & $.07 * *$ & $-.14 * *$ & $-.15 * *$ \\
\hline Education & $-.09 * *$ & .04 & -.04 & .01 \\
\hline Household Income & -.01 & $.06^{*}$ & .00 & -.01 \\
\hline Rural Child & -.02 & $-.07 * *$ & .04 & -.04 \\
\hline Rural Adult & .00 & $.08 * *$ & -.02 & -.03 \\
\hline White & $-.10 * *$ & .01 & $.07^{*}$ & .03 \\
\hline Black & .00 & -.01 & -.04 & $-.17 * *$ \\
\hline Protestant & -.04 & $-.04 *$ & .04 & $-.15^{* *}$ \\
\hline Catholic & .03 & .03 & -.01 & .00 \\
\hline $\mathrm{R}^{2}$ & $.25^{* *}$ & $.36 * *$ & $.23 * *$ & $.34 * *$ \\
\hline $\begin{array}{l}\text { Total change in } \mathrm{R}^{2} \text { when } \\
\text { added in } 2 \text { nd Step }\end{array}$ & Environment & Gun Control & Death Penalty & Gay Marriage \\
\hline Cultural orientations & $.15^{* *}$ & $.21 * *$ & $.14 * *$ & $.22 * *$ \\
\hline Demographics & $.02 * *$ & $.01 * *$ & .00 & $.04 * *$ \\
\hline
\end{tabular}

$N=1843{ }^{* *} p<.01,{ }^{*} p<.05$ for a two-tailed significance test.

${ }^{\dagger}$ For these analyses, two separate regressions were run, varying which group of variables was entered together on the second step. 
Table 3. Comparison of Standardized Coefficients and Change in $\mathbf{R}^{2}$ for Liberal-Conservative SelfIdentification, Partisanship, and Cultural Worldviews on Policy Attitudes

\begin{tabular}{|c|c|c|c|c|}
\hline Predictor & Environment & Gun Control & Death Penalty & Gay Marriage \\
\hline Conservative & -.05 & .00 & .00 & $-.24 * *$ \\
\hline GOP & $-.16^{* *}$ & $.08 * *$ & .04 & -.02 \\
\hline Hierarchy & $-.30 * *$ & $-.35 * *$ & $.33^{* *}$ & $-.47 * *$ \\
\hline Individualism & $-.11 * *$ & $-.26 * *$ & $.16^{* *}$ & $.12^{* *}$ \\
\hline $\mathrm{R}^{2}$ & $.27 * *$ & $.32 * *$ & $.24 * *$ & $.35^{* *}$ \\
\hline $\begin{array}{l}\text { Total change in } \mathrm{R}^{2} \text { when } \\
\text { added in } 2 \text { nd Step }\end{array}$ & Environment & Gun Control & Death Penalty & Gay Marriage \\
\hline Cultural orientations & $.08 * *$ & $.19^{* *}$ & $.14^{* *}$ & $.12^{* *}$ \\
\hline Pol. identity (Cons., GOP) & $.02 * *$ & $.01 * *$ & .00 & $.04 * *$ \\
\hline
\end{tabular}

$N=1843{ }^{* *} p<.01, * p<.05$ for a two-tailed significance test.

${ }^{\dagger}$ For these analyses, two separate regressions were run, varying which group of variables was entered together on the second step. 
Table 4. Comparison of Standardized Coefficients for Liberal/Conservative Self-Identification, Partisanship, and Cultural Worldviews on Policy Attitudes at Low, Medium, and High Levels of Political Knowledge (PK) ${ }^{\dagger}$

\begin{tabular}{|c|c|c|c|c|c|c|c|c|c|c|c|c|}
\hline \multirow[b]{2}{*}{ Political Scale } & \multicolumn{3}{|c|}{ Environment } & \multicolumn{3}{|c|}{ Gun Control } & \multicolumn{3}{|c|}{ Death Penalty } & \multicolumn{3}{|c|}{ Gay Marriage } \\
\hline & Low PK & Med PK & High PK & Low PK & Med PK & High PK & Low PK & Med PK & High PK & Low PK & Med PK & High PK \\
\hline Cons & -.10 & $-.19 * *$ & $-.41 * *$ & -.04 & $-.17 * *$ & $-.45 * *$ & -.10 & $-.19 * *$ & $-.41 * *$ & $-.26 * *$ & $-.38 * *$ & $-.51 * *$ \\
\hline GOP & $-.14^{* *}$ & $-.27 * *$ & $-.24 * *$ & -.05 & $-.26 * *$ & $-.18 * *$ & $-.14^{* *}$ & $-.27^{* *}$ & $-.25^{* *}$ & -.02 & $-.10 * *$ & $-.17 * *$ \\
\hline $\mathrm{R}^{2}$ & $.03 * *$ & $.16^{* *}$ & $.35 * *$ & .01 & $.14^{* *}$ & $.33 * *$ & $.04 * *$ & $.16^{* *}$ & $.35 * *$ & $.07^{* *}$ & $.19 * *$ & $.39 * *$ \\
\hline Cultural Scale & Low PK & Med PK & High PK & Low PK & Med PK & High PK & Low PK & Med PK & High PK & Low PK & Med PK & High PK \\
\hline Hierarchy & $-.26 * *$ & $-.40 * *$ & $-.57 * *$ & $-.26 * *$ & $-.40 * *$ & $-.39 * *$ & $.18 * *$ & $.40 * *$ & $.41^{* *}$ & $-.37 * *$ & $-.52 * *$ & $-.72 * *$ \\
\hline Individualism & -.04 & $-.10 * *$ & -.07 & $-.17 * *$ & $-.20 * *$ & $-.38 * *$ & $.18 * *$ & $.10 * *$ & $.26^{* *}$ & $.15^{* *}$ & $.11 * *$ & .06 \\
\hline $\mathrm{R}^{2}$ & $.07 * *$ & $.20 * *$ & $.39 * *$ & $.11 * *$ & $.27 * *$ & $.50 * *$ & $.07 * *$ & $.20 * *$ & $.38 * *$ & $.14 * *$ & $.23 * *$ & $.47 * *$ \\
\hline
\end{tabular}

${ }^{* *} p<.01, * p<.05$ for a two-tailed significance test.

${ }^{\dagger}$ Bold typeface indicates that there is a significant interaction between the specified independent variable and political knowledge with respect to the specified policy attitude, whereas regular typeface indicates the absence of a significant interaction. The $n$ for all variables in equations was 540 for low knowledge, 946 for medium, and 347 for high. 
Table 5. Comparison of Standardized Coefficients and Changes in $\mathbf{R}^{2}$ for Socio-Demographic Characteristics and Cultural Worldviews in Explaining Liberal/Conservative Self-Identification and Partisanship

\begin{tabular}{|c|c|c|c|c|}
\hline \multirow[b]{2}{*}{ Predictor } & \multicolumn{2}{|c|}{ Conservative } & \multicolumn{2}{|c|}{ GOP } \\
\hline & Model 1 & Model 2 & Model 1 & Model 2 \\
\hline Female & -.04 & .03 & $-.06 * *$ & .00 \\
\hline Age & -.02 & -.04 & $-.12 * *$ & $-.14 * *$ \\
\hline Education & -.12 & .01 & -.05 & .05 \\
\hline Household Income & .03 & .01 & .06 & .04 \\
\hline Rural Child & .05 & .01 & .00 & -.03 \\
\hline Rural Adult & .04 & .01 & .03 & .01 \\
\hline White & .07 & .01 & $.13 *$ & .09 \\
\hline Black & -.08 & -.01 & $-.24 * *$ & $-.19 * *$ \\
\hline Protestant & $.15^{* *}$ & .05 & $.11 * *$ & .03 \\
\hline Catholic & .06 & .00 & .00 & $-.05^{*}$ \\
\hline Hierarchy & -- & $.47 * *$ & -- & $.42 * *$ \\
\hline Individualism & -- & .02 & -- & .01 \\
\hline $\mathrm{R}^{2}$ & $.08 * *$ & $.30 * *$ & $.14 * *$ & $.31 * *$ \\
\hline $\begin{array}{l}\text { Cha } \mathrm{R}^{2} \text { When Added } \\
\text { in } 2 \text { nd Step }\end{array}$ & \multicolumn{2}{|c|}{ Conservative } & \multicolumn{2}{|c|}{ GOP } \\
\hline Cultural orientations & \multicolumn{2}{|c|}{$.22 * *$} & \multicolumn{2}{|c|}{$.17^{* *}$} \\
\hline Demographics & \multicolumn{2}{|c|}{$.02 * *$} & \multicolumn{2}{|c|}{$.08 * *$} \\
\hline
\end{tabular}

$N=1843{ }^{* *} \mathrm{p}<.01, * \mathrm{p}<.05$ for a two-tailed significance test.

${ }^{\dagger}$ For these analyses, two separate regressions were run, varying which group of variables was entered together on the second step. 